Cahiers $d u$ MONDE RUSSE

\section{Cahiers du monde russe}

Russie - Empire russe - Union soviétique et États indépendants

$50 / 4 \mid 2009$

Varia

\title{
Serguei Alex. Oushakine, The Patriotism of Despair
}

\section{Françoise Daucé}

\section{OpenEdition \\ Journals}

Édition électronique

URL : https://journals.openedition.org/monderusse/7206

DOI : $10.4000 /$ monderusse. 7206

ISSN : $1777-5388$

Éditeur

Éditions de l'EHESS

Édition imprimée

Date de publication : 15 décembre 2009

Pagination : 873-876

ISBN : 978-2-7132-2261-0

ISSN : $1252-6576$

\section{Référence électronique}

Françoise Daucé, "Serguei Alex. Oushakine, The Patriotism of Despair », Cahiers du monde russe [En ligne], 50/4 | 2009, mis en ligne le 12 janvier 2011, consulté le 03 septembre 2022. URL : http:// journals.openedition.org/monderusse/7206; DOl : https://doi.org/10.4000/monderusse.7206

Ce document a été généré automatiquement le 3 septembre 2022

Tous droits réservés 


\title{
Serguei Alex. Oushakine, The Patriotism of Despair
}

\author{
Françoise Daucé
}

\section{RÉFÉRENCE}

Serguei Alex. OUSHAKINE, The Patriotism of Despair. Nation, War and Loss in Russia.

New York : Cornell University Press, 2009, 299 p.

1 Serguei Oushakine, enseignant en langue et littérature slaves à l'université de Princeton, étudie dans cet ouvrage les conséquences de la chute de l'URSS sur les comportements sociaux en Russie aujourd'hui. Plus précisément, il s'intéresse aux individus, aux objets et aux valeurs disparus avec le soviétisme, ainsi qu'aux conséquences de cette extinction sur les pratiques collectives dans la société russe. Il dessine ainsi, en creux, le tableau des liens sociaux créés par ce qui n'est plus. Originaire de Barnaul, capitale de la région de l'Altaï (Sibérie), l'auteur a mené une enquête ethnographique approfondie dans sa région natale. Il a réalisé de nombreux entretiens avec des néocommunistes, des vétérans des guerres d'Afghanistan et de Tchétchénie, des nationalistes russes et des mères de soldats. Ces groupes sociaux, divers à première vue, ont en commun d'avoir subi la disparition de l'Union soviétique en y perdant leur statut et leur reconnaissance sociale. Ce déclassement n'a pu être compensé par un État incapable de gérer les conséquences traumatiques de ses actes.

2 Oushakine s'intéresse aux pratiques quotidiennes qui permettent à ces groupes de subsister sans le soutien des institutions publiques. Il identifie à la fois des ancrages symboliques et des « objets transitionnels », pour reprendre les termes de Winnicott, qui permettent aux citoyens déclassés de se maintenir en société. De son point de vue, durant les phases de transition personnelle et collective, les séquelles d'un monde disparu, la survivance d'objets et d'épisodes du passé assurent une continuité dans la vie des individus. L'ouvrage examine les formes populaires symboliques utilisées pour pallier l'affaiblissement de l'État russe. Dans les entretiens qu'il a recueillis, l'auteur note 
qu'à défaut de posséder un vocabulaire sociopolitique clairement balisé, de nombreuses personnes interviewées utilisent un langage lié à la famille et à l'amitié (maternité, fraternité...) pour évoquer les nouveaux aspects des relations postsoviétiques. En l'absence d'institutions civiques fortes, c'est la logique de réseau qui a fonctionné pour dépolitiser, domestiquer et intégrer le traumatisme et la violence dans la vie quotidienne. Ce constat n'est pas propre à la Russie. Comme le soulignent les anthropologues ${ }^{1}$, l'absence de modèle positif de développement social et politique conduit souvent à une reconstruction des activités économiques, politiques et sociales autour de notions et de pratiques de proximité. Les études sur le rôle de l'amitié dans les relations sociales ${ }^{2}$ ont mis en évidence que la tentation de se replier sur les liens du proche est une caractéristique commune aux groupes qui se sentent menacés.

3 Dans le premier chapitre, consacré à l'appropriation du capitalisme (« Repatriating capitalism »), Oushakine montre, à partir d'entretiens avec des néocommunistes, que la fragmentation des espaces public et privé après la chute de l'URSS a conduit à l'émergence d'une nouvelle mythologie de la culture russo-soviétique. Étudiant la dislocation de l'espace public imposée par les développements capitalistes à Barnaul, il indique que ces transformations ont été perçues comme le fruit d'une invasion étrangère. En réponse, les ruptures imposées par le capitalisme ont favorisé la recherche de liens et de connexions de proximité. Pour l'auteur, les pertes subies par la population n'ont pas conduit à un désengagement. Au contraire, la mise en commun d'expériences négatives a permis de créer de nouvelles formes de solidarité. Ainsi, la globalisation du capital et ses conséquences matérielles ont été compensées par le repli sur une communauté nationale fermée. Imaginer une duperie émanant de l'extérieur (" nous avons été trompés») a permis de localiser ailleurs les sources de responsabilités et de redécouvrir les « vraies » valeurs de la culture russo-soviétique construite comme un «bien inaliénable ».

«La Tragédie russe. Du traumatisme ethnique à la vitalité ethnique » est le titre du deuxième chapitre. Initialement, l'expression "tragédie russe» était utilisée pour qualifier les années soviétiques. À partir de la fin des années 1990, elle est appliquée à l'expérience postsoviétique. Le concept d'ethnie constitue un substitut pratique à la notion de classe du marxisme orthodoxe. Il offre un instrument compréhensible de classification sociale et une certaine vision du progrès (le " développement ethnique »). L'auteur présente le renouveau des théories de Lev Gumil'ev (notion d'etnosfera comme rencontre entre un peuple et un territoire pour former une ethnie) et souligne que l'histoire récente de la nation a été transformée en génocide du peuple russe. Il s'interroge sur le nationalisme académique qui a surgi dans le contexte social de la Russie postsoviétique, et notamment dans la production académique locale. Oushakine a interrogé des enseignants de l'université de Barnaul. Il étudie ainsi les travaux d'un certain Filippov, philosophe de cette université et antisémite déclaré, se revendiquant de «l'école vitaliste » qui se soucie de la survie de l'ethnos russe ${ }^{3}$. Cette section permet à l'auteur de montrer la séparation analytique opérée en Russie entre l'État et l'ethnie, mais on peut regretter qu'elle ne soit pas alimentée plus amplement par des témoignages sur la réception de ces idées dans la population de Barnaul.

Dans le troisième chapitre, Oushakine s'intéresse au sort des vétérans de la guerre de Tchétchénie à Barnaul. L'État les a rapidement abandonnés à la fin de leur service et l'ambiguïté du statut légal du conflit a aggravé leur situation. Ainsi, après avoir transformé ses citoyens en combattants, l'État ne s'est pas préoccupé de leur retour à la vie civile. L'auteur retrace l'histoire des politiques d'aide publique aux vétérans, depuis 
les avantages matériels accordés en Union soviétique jusqu'aux exemptions fiscales (avec leurs effets pervers) données aux afgancy; il expose leurs difficultés de réinsertion professionnelle, aussi bien dans les services publics, où ils sont déconsidérés, que dans les entreprises de sécurité privées, où ils peinent à s'adapter. Oushakine souligne encore la tendance de ces vétérans à valoriser un modèle utopique de communauté autarcique fondée sur des liens d'amitié et de reconnaissance liés au patriotisme, en se référant parfois au modèle des rapports sociaux dans les prisons : « c'est un paradoxe, mais dans les prisons, on respecte ceux qui ont défendu la patrie ", disent-ils.

6 L'auteur étudie l'action du Comité des mères de soldats de Barnaul dans le chapitre suivant, intitulé "Mères, objets et relations: Unies par la mort». Il souligne l'attachement des mères à la symbolique des liens familiaux et leur tendance à « domestiquer » les relations sociales. Son analyse est fondée sur la lecture de deux cents lettres adressées au comité de Barnaul dans les années 1990. La richesse de ces sources locales lui permet de compléter la littérature existante généralement consacrée aux Comités de mères de soldats de Moscou et Saint-Pétersbourg. Oushakine met en évidence le caractère obsessionnel de l'attachement des mères pour la tombe de leur fils, l'érection de mémoriaux et la production d'objets de deuil (notamment des albums du souvenir). S'appuyant là encore sur les travaux de Winnicott, il analyse la mémorialisation à travers ces tombes qui permettent d'extérioriser la perte subie et de rompre avec le silence de la société. Les mères de soldats de l'Altaï refusent toute association avec les mouvements politiques existants et se replient sur le " patriotisme du désespoir », avec ses références évidentes au sang et au sol.

7 L'ouvrage montre ainsi les différentes formes de patriotisme du désespoir qui émergent autour d'une expérience commune de perte. Oushakine analyse comment la fragmentation des réseaux soviétiques et la transformation radicale des institutions d'État ont conduit les citoyens à rechercher des idéaux auxquels se raccrocher. Il décrypte les rituels de reconnaissance et les échanges socio-symboliques susceptibles de créer des liens de réciprocité, et estime que l'expérience traumatique génère de nouveaux principes intégrateurs qui fondent l'édifice social. La domestication et la personnalisation de la perte sont utilisées comme moyen pour organiser des groupes " amorphes ». Cependant, elles sont la source d'une quête émotionnelle de revanche et de rétribution plutôt que de responsabilité (accountability) et de justice. Les griefs du quotidien se sont substitués aux questions de responsabilité politique, comme si un contenu positif ne pouvait être trouvé pour recréer un sens du vivre ensemble. La communauté s'appuie sur l'expérience partagée de la perte pour établir ses nouvelles frontières, effectuant ainsi un travail par la négative. L'ouvrage dans son ensemble est donc empreint d'un profond pessimisme. Celui-ci est en partie le fruit des choix méthodologiques de l'auteur qui concentre son ouvrage sur le récit des victimes du changement de régime et analyse leur désespoir à l'aune d'un idéal démocratique qui n'est pas advenu. Oushakine décode avec subtilité les nouvelles relations sociales de ces communautés unies dans l'échec, mais sans élargissement à des considérations sur les enjeux marchands, civiques, amicaux ou religieux des nouvelles relations observées dans la société russe. Ces enjeux complémentaires apparaissent pourtant au gré des entretiens cités par l'auteur, mais ne sont pas vraiment mis en lumière ni analysés, cantonnant le patriotisme à la déploration de la perte sans mentionner ses apports. Il s'agit d'une exploration subtile des réalités de la société russe contemporaine, qui reste cependant partielle et mériterait d'être complétée par des travaux ultérieurs de même inspiration. 


\section{NOTES}

1. Sarah Franklin, Susan McKinnon, eds., Relative Value: Reconfiguring Kinship Studies, Durham, NC : Duke University Press, 2001.

2. Voir par exemple Janet Carsten, Cultures of Relatedness: New Approaches to the Study of Kinship, Cambridge : Cambridge University Press, 2000.

3. Guido Cimino, François Duchesneau, Vitalisms from Haller to the Cell Theory, Firenze : Leo S. Olschki Editore, 1997. 